\title{
Probing nanomechanical properties from biomolecules to living cells
}

\author{
S. Kasas · G. Dietler
}

Received: 7 January 2008 / Accepted: 9 January 2008 / Published online: 22 January 2008

(C) Springer-Verlag 2008

\begin{abstract}
Atomic force microscopy is being increasingly used to explore the physical properties of biological structures. This technique involves the application of a force to the sample and a monitoring of the ensuing deformation process. The available experimental setups can be broadly divided into two categories, one of which involves a stretching and the other an indentation of the organic materials. In this review, we will focus on the indentation technique and will illustrate its application to biological materials with examples that range from single molecules to living cells.
\end{abstract}

Keywords AFM - Mechanical properties · Cell · Biology · Nanomechanics

\section{Introduction}

One of the greatest achievements of the past 30 years in the diverse fields of microscopy and proteomics has been the revelation of correlations between the shapes of microscopic structures and their function. However, the configuration of a biomolecule is not the sole determinant of its physiological function, factors such as chemical composition, electrical charge distribution, and mechanical proper-

S. Kasas · G. Dietler

Laboratoire de Physique de la Matière Complexe, EPFL,

CH-1015 Lausanne, Switzerland

\section{S. Kasas $(\square)$}

Département de Biologie Cellulaire et de Morphologie, Université de Lausanne,

rue du Bugnion 9,

CH-1005 Lausanne, Switzerland

e-mail: sandor.kasas@epfl.ch ties being also important. If the mechanical properties of mesoscopic structures such as bone, tooth, and tendons are important for their functions, then it is reasonable to surmise that these properties will be equally important on the nanometric scale and will determine the behavior of single proteins and their assemblies. The recent development of nano-manipulation tools such as optical tweezers and atomic force microscopy (AFM) now permits a study of the mechanical properties of structures on the micro- to nanometric scale. Endeavors to unveil the mechanical properties of single molecules or their assemblies are made with a view not only of improving our understanding of the nano-world but also of developing new and more sophisticated diagnostic tools. The mechanical properties of single cells are known to reflect their physiological state and to be altered in some pathological states such as cancer. Hence, it should be possible to correlate a change in a mechanical property with a structural defect at the molecular level. Several tools are now available for measuring the mechanical properties of microscopic structures. These include optical or magnetic tweezers, biomembrane force probes, gel columns, and AFM. In this review, we will focus on AFM, which, by virtue of its versatility and simplicity, is the technique most widely used for circumstance is reflected in the AFM literature, which comprehends an increasing number of reports dealing with the mechanical properties of single cells, bacteria, viruses, and proteins. Examples will be drawn from the field of biological nanomechanics. They will relate to measurements that have been made using the indentation technique, which probes the elastic properties of the sample.

The first part of the review deals with measurements that have been made on isolated proteins or organelles and the second with measurements pertaining to entire cells and their equipment such as lamelipodia, axons, vesicles, or 
membranes. Appendices 1 and 2 include a definition of the relevant mechanical principles and an explanation of the operational mode of AFM.

\section{Globular proteins}

AFM indentation experiments with globular proteins are relatively scarce. Pioneering studies of this kind were conducted by Radmacher et al. [73] in 1994. The protein analyzed was lysozyme, which is involved in the lysis of the bacterial wall. Incidentally, lysozyme was also the first enzyme to have its atomic structure determined by X-ray diffraction crystallography. Radmacher et al. conducted numerous experiments to explore the adhesion, viscosity, and stiffness of individual lysozyme molecules. The indentation curves* obtained were fitted to the Hertz model and corresponded to a Young's modulus* of $0.5 \mathrm{GPa}$.

Later, Ikai et al. performed a comprehensive series of compression experiments on bovine carbonic anhydrase $[3,35]$. This enzyme catalyzes the hydration of $\mathrm{CO}_{2}$ and the dehydration of $\mathrm{H}_{2} \mathrm{CO}_{3}$. It therefore plays a pivotal role in gaseous exchange processes and in the regulation of $\mathrm{pH}$. Carbonic anhydrase consists of 259 amino acid residues which are mostly folded into beta sheets. Ikai et al. compressed and stretched the enzyme by AFM and validated their data by molecular dynamic modeling. In contrast to Radmacher et al., Ikai et al. fitted their data to Tatara's model, which basically considers the soft biological sample to be sandwiched between two non-deformable plates. The experimental data fitted the model up to a deformation of $50 \%$ and yielded a Young's modulus of $75 \mathrm{MPa}$.

The scanning of soft biological objects, such as proteins, by AFM inevitably induces their deformation. If the applied load is too large, irreversible structural modifications occur which impair the function of the protein. In an attempt to quantify the maximal loads that can be supported by proteins, Kodama et al. $[50,51]$ monitored the change in fluorescence of fluorescently tagged proteins under a compression force* applied by AFM. Under these conditions, the green fluorescence was quenched, and at a force of about $5 \mathrm{nN}$, the fluorescent molecules disrupted.

More recently, Parra et al. [72] determined the Young's modulus of lactate oxidase by AFM. This $80-\mathrm{kDa}$ enzyme effects the conversion of lactate to pyruvate, and vice versa, in many organisms, including plants and animals. Lactate oxidase was chosen because its physicochemical properties are relatively well known and because it is widely used in bioanalytical devices for the determination of lactate in the food industry. Single molecules of lactate oxidase were indented with cantilevers of varying stiffness. The resulting indentation curves were then fitted to the Hertz model to yield values for the Young's modulus in the range of 500-800 MPa.
The topic of protein compression has been comprehensively reviewed by Ikai [36] and Ikai et al. [37]. This type of measurement raises important questions, namely, does it make sense to determine Young's modulus for a single molecule? And to what extent can continuum mechanics be applied to a single protein with a neglect of the effects related to atomic details? Nowadays, AFM measurements of this kind pose no insurmountable experimental challenge. However, the data are not open to unequivocal interpretation and can be validated only by applying sophisticated computational models (based on molecular dynamics). The questionable relevance of the measurements and the need for mathematical expertise in interpreting the data probably account for the dearth of publications dealing with experiments of this kind.

\section{Protein filaments}

Protein filaments are constituents of the cellular cytoskeleton and of extracellular structures such as ligaments and tendons. Hence, their mechanical properties are of paramount importance in physiology.

The cytoskeleton is a highly dynamic structure, which is involved in processes such as cell division, the transport of organelles, and the maintenance of cell shape. It is composed of three major classes of filament: actin filaments are the finest, with a diameter of about $6 \mathrm{~nm}$; intermediate filaments are somewhat thicker, with a diameter of $10 \mathrm{~nm}$; and microtubule are the largest, with an outer diameter of $25 \mathrm{~nm}$. A knowledge of the individual mechanical characteristics of these filaments is crucial for an understanding of the global properties of living cells. Moreover, several antimitotic drugs that are used in cancer therapy interfere with components of the cytoskeleton. Hence, this field is of particular interest to the pharmaceutical industry. Numerous methodologies have been employed to measure the mechanical properties of single cytoskeletal filaments, among which AFM figures poorly. This topic has been reviewed by Kasas and Dietler [42].

Microtubules are important in cell division and mitosis, being involved in the segregation of chromosomes within the mitotic and meiotic spindles. They also serve as tracks for the intracellular movement of components such as vesicles and mitochondria (for a recent review of this topic, see [97]). Microtubules also participate in the formation of cilia and flagella within highly specialized cells such as sperm and pillar cells of the inner ear. Their mechanical properties, thus, have a profound bearing on the function of these cells.

The first AFM measurements of microtubule stiffness were made by Vinckier et al. [94] in 1995. They involved the recording of force-distance* curves on the top of a microtubule in the absence or presence of different 
concentrations of glutaraldehyde. Glutaraldehyde is a chemical fixative, which, by cross-linking proteins, effects their stabilization. The measurements yielded values for Young's modulus in the range of 1-12 MPa. These "low" values probably reflect the highly anisotropic nature of the structures and the fact that shear* (i.e., the stiffness of the links between the protofilaments) rather than Young's modulus was being evaluated.

Several years later, a slightly different approach was adopted to measure the shear modulus* of microtubules [47], which was found to be about 1.4 MPa. Microtubules were deposited upon an electron-beam-induced, lithographically modified substrate, as depicted in Fig. 1. The elastic deformation of the microtubules bound to this surface, which contained holes of different size, was determined by AFM. The boundary conditions of the suspended microtubule, viz., the number of protofilaments that were attached to the surface, was estimated by finite-element modeling [43].

DePablo et al. [18] used AFM to measure the mechanical properties of microtubules that were stabilized with taxol, which is also used clinically as a mitotic inhibitor in cancer chemotherapy. The force-distance curves were recorded with the microtubule in both the linear (or elastic) state (i.e., when its initial shape was restored after the measurement) and the non-linear (or plastic) one (i.e., when the measurement induced its permanent deformation). The plastic state corresponds to a collapse of the microtubule under the load exerted by the tip of the cantilever. In the elastic state, the microtubule was deemed to behave like a spring, with a spring constant* of about $0.1 \mathrm{~N} / \mathrm{m}$. Finiteelement modeling was then used to calculate Young's modulus, which was found to be about $0.8 \mathrm{GPa}$. Measurements made with the microtubules in the plastic state yield a crude estimate of the rupture force, which was in the order of several hundred piconewtons.

Tau protein isoforms are known to aggregate into pathologically relevant "paired helical filaments" which are the hallmarks of Alzheimer's and other neurodegenerative diseases [57]. In addition to their pathological relevance, tau proteins also play an important role in the

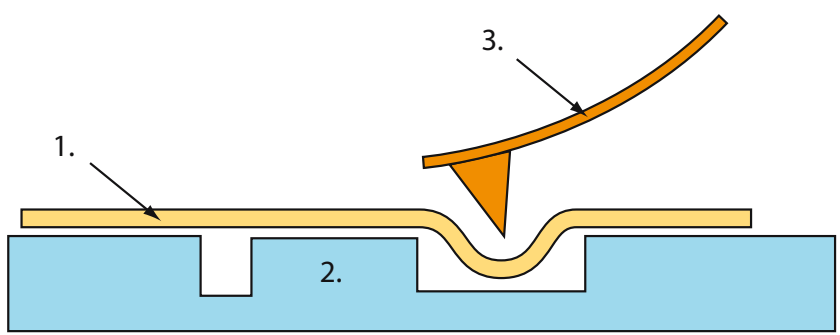

Fig. 1 If filamentous structures, such as microtubules or intermediate filaments (1), are suspended above nanofabricated supports (2), then it is possible to calculate not only Young's modulus but also the shear modulus from the indentation data that are recorded by AFM via the tip of the instrument (3) stabilization of microtubules [19]. To ascertain whether tau binding modulates the elastic properties of microtubules, Shaap et al. [82] made AFM measurements on these structures after tau decoration. The data gleaned from the indentation curves were confirmed by finite-element modeling. Tau decoration elicited no change in the elastic properties of the microtubules. However, tau binding increased their resistance in the non-elastic (plastic) state, with a consequent increase in the rupturing force.

Microtubules are prone to intermittent phases of growth and rapid depolymerization, thereby creating a situation that is referred to as "dynamic instability." This process is closely linked to the hydrolysis of guanosine triphosphate (GTP), which is bound between tubulin dimers in the microtubular lattice [65]. Microtubules containing hydrolyzed GTP are intrinsically unstable, and their mechanical properties in this state are largely unknown. Using a slowly hydrolyzable analogue of GTP guanylyl-alpha-betamethylenediphosphonate to mimic GTP-containing protofilaments, Munson et al. [66] measured the effective spring constant, which is related to Young's modulus. The value determined $(0.172 \mathrm{~N} / \mathrm{m})$ was twofold higher than that for taxol-stabilized microtubules (for a definition of the spring constant, Young's modulus, and their incomparability the reader is referred to Appendices 1 and 2).

For additional information relating to AFM measurements on microtubules, the interested reader is referred to [81, 83-85].

Intermediate filaments are apolar structures, which are assembled from 45-nm-long coiled-coil dimmers. Among other functions, they play an essential role in maintaining the shape and mechanical stability of cells. Recently, it has been suggested that the axial sliding of dimmers relative to one another within a filament may medicate the transduction of mechanical signals [63] from the plasma membrane to the nucleus wherein a specific response may be triggered [7].

Guzmann et al. [27] have used AFM to measure the bending and sliding properties of single intermediate filaments of vimentin. The experimental setup was similar to that which the same authors had developed for measuring the mechanical properties of microtubules (Fig. 1). Single filaments were suspended over a porous membrane and elastically deformed by AFM. The bending modulus* of non-stabilized filaments lay in the range of 300-400 MPa and depended on their length. The authors accounted for this finding by postulating that the constitutive dimmers were capable of sliding axially relative to each other. To confirm this hypothesis, the experiments were repeated using glutaraldehyde-stabilized filaments within which individual dimmers were cross-linked to prevent their sliding. The bending modulus of these glutaraldehyde-stabilized filaments was two to threefold 
higher than that of the non-stabilized ones. Young's modulus for intermediate filaments of vimentin was calculated to be at least $900 \mathrm{MPa}$.

Collagen fibers are abundant within extracellular matrices wherein, by virtue of their high tensile strength, they serve as mechanically supportive structures. They also constitute a major component not only of structures such as fascia, ligaments, and tendons but also of cartilage, bone, and teeth. During the past decade, several studies have been undertaken to elucidate the substructure of collagen and to relate this substructure to the function and mechanical properties of the polymer. However, owing to the hierarchical structure of collagen, it has been difficult to pinpoint the relative contributions of different organizational levels to the mechanical behavior of the polymer as a whole. This circumstance accounts for the broad range of reported values for Young's modulus (1-8 GPa). In an attempt to streamline the system, Yang et al. [101] deposited unfixed and glutaraldehyde-fixed collagen fibers upon a microfabricated substrate and made AFM indentation measurements on the suspended fragment. On the basis of these measurements, Young's modulus was calculated to be $5 \mathrm{GPa}$ for native fibers and $14 \mathrm{GPa}$ for glutaraldehyde-fixed ones.

\section{Isolated cellular structures}

Chromosomes have been used by Jiao and Schaffer [41] to assess the reliability of height and volume measurements that are determined using the three different imaging modes of AFM (contact, tapping, and force mapping). The investigation was prompted by the fact that if a sample is soft, the AFM tip will indent it, with the consequence that the reported heights and volumes will be underestimated. Human metaphase chromosomes were used to model a soft sample. In the contact mode, the measured heights and volumes of the chromosomes depended greatly on the setpoint force. The degree to which the chromosomes were indented increased with an increase in the imaging force, which resulted in corresponding decreases in their recorded heights. In the tapping mode, the recorded height varied in a complex manner as a function of the set-point amplitude. The most reliable topographic images were obtained using the force-mapping mode, the chromosomes being reconstructed from the contact points on the force-distance curves. The underlying principle of this "zero force" topographic image is depicted in Fig. 2. From images of the latter kind, Young's modulus for chromosomes was calculated to be about $0.4 \mathrm{MPa}$.

Cellular secretory products are stored within secretory granules or vesicles and are released by a complex and incompletely understood process, which is referred to as exocytosis. This fundamental physiological process appeared at an early stage of evolution, and most of the
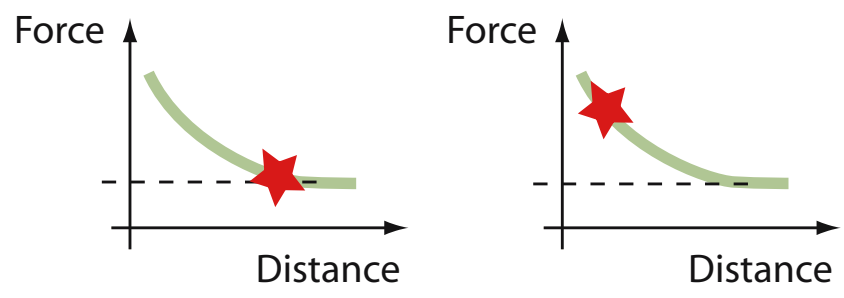

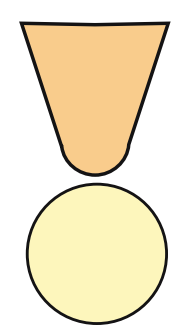

a

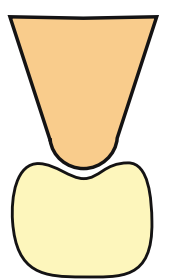

b
Fig. 2 In the force-mapping mode, successive force-distance curves are recorded over the entire surface of the sample. A topographic image can thus be generated at different forces values (i.e., at different cantilever deflections). The topographic image that embraces the position of the piezo at or near the contact point (a) is referred to as the "zero-force image". Any topographic image that is recorded at a slightly higher force will be deformed, owing to the compliance of the sample, as depicted in (b). The asterisk in each of the two forcedistance curves represents the force at which the corresponding topographic image was obtained

molecular mechanisms that are manifested in simple unicellular organisms, such as yeast, have been conserved in more complex systems, such as the mammalian brain [10]. The mechanical properties of neurotransmitter-secreting vesicles were investigated by Laney et al. [54] in 1997. It has been assumed that the stiffness of vesicles determines the mechanism of exocytosis. To test this tenet, the authors applied AFM in the force-mapping mode to cholinergic synaptic vesicles that were isolated from the electric organ of a marine ray (Torpedo californica) and immersed in solutions of different osmolarities and chemical compositions. Young's modulus was calculated and fell within the range of $200 \mathrm{kPa}-1.3 \mathrm{MPa}$. The central portion of the vesicles was found to be considerably stiffer than the periphery, and this central stiffness increased as the calcium concentration in the bathing medium was raised. The authors hypothesized that calcium ions bind to and crosslink centrally located proteoglycans, thereby producing a stiff network in this region of the vesicles.

At almost the same time, Parpura and Fernandez [71] employed a similar technique to study the mechanical properties of submicrometer-sized secretory granules that were isolated from rat mast cells. These secretory granules were found to contain an insoluble matrix that reversibly shrinks and swells in response to ion exchange with different cations. Depending on the valency of the cations in 
the bathing medium, Young's modulus for the matrix varied between $37 \mathrm{kPa}$ and $4.3 \mathrm{MPa}$. Cationic valency simultaneously influenced the volume of the matrix, which was inversely related to Young's modulus in a manner similar to that predicted for the elasticity of weakly cross-linked polymers.

Liposomes are important drug delivery vehicles, and they also serve as useful models for the cell membrane. The mechanical properties of liposomes are obviously important for their role in drug delivery. And as a model for the cell membrane, they can be used to assess its global physical properties per se and under the influence of external agencies. In 2004, Liang et al. [61] studied unilamellar phosphatidylcholine liposomes by AFM. By fitting the indentation curves to the Hertz model, Young's modulus and the bending modulus were calculated to be about $2 \mathrm{MPa}$ and $0.21 \times 10^{-19} \mathrm{~J}$, respectively (details about the significance of bending modulus of lipid bilayers can be found in [61]). The same authors then studied the influence of cholesterol on the mechanical properties of the phosphatidylcholine liposomes [60]. This issue is important for the pharmacological industry, as cholesterol is known to affect bilayer stability. It is also of physiological relevance, as cholesterol-enriched microdomains (or rafts) feature in several cellular processes, such as signal transduction, cellular adhesion, and infection by pathogens. The addition of cholesterol to the bathing medium led to a dramatic increase in the mechanical stiffness of the liposomes. By a careful analysis of the force-distribution curves, the authors were able to follow the rupturing of the liposome membranes during the indentation process (Fig. 3).

\section{Viruses}

The mechanical properties of viral capsids are important for the survival of the organism and, thus, for its infectivity. During the past decade, numerous AFM investigations have been conducted to demonstrate the mechanical properties of viruses. In this review, only the most recent studies will be mentioned. But for a fulsome overview of the pertinent literature, the reader is referred to the publication by Roos [77]. For a detailed handling of the finite-elements modeling* of viral capsids, the publications by Gibbons and Klug [25] and Klug et al. [48, 49] are recommended.

In 2006, Michel et al. [64] used AFM to determine the elastic properties of wild-type and mutant strains of the cowpea chlorotic mottle virus. Nano-indentation measurements were made both on empty capsids and on those that were filled with an RNA genome. As anticipated, the filled capsids were more resistant to indentation than the empty ones. Nevertheless, irrespective of whether the capsids were empty or filled, both the wild-type and the mutant varieties were highly elastic, viz., they recovered their initial shape after deformation. Interestingly, a single point mutation in the protein of which the capsid is composed led to a modification in its stiffness. The indentation measurements were interpreted in the light of finite-element modeling, which was based on homogeneous elastic thin-shell components, as depicted in Fig. 4. This analysis yielded a Young's modulus of 140 for the wild-type viral capsid and one of $190 \mathrm{MPa}$ for the mutant form.

The tobacco mosaic virus has been well characterized [6]. At a low level of resolution, it has a rod-like shape, which renders theoretical calculations of its mechanical properties, such as the elastic modulus, relatively easy. AFM indentation measurements of the tobacco mosaic virus have revealed its Young's modulus to be about $6 \mathrm{GPa}$ [86].

Like Michel et al. [64], Ivanovska et al. [38-40] have also used AFM to investigate the extent to which the genome of viral capsids contributes to the overall stiffness of the organism. They measured the mechanical properties of $\lambda$-phages that were either empty or filled with wild-type DNA to their full or a partial extent. Fully filled $\lambda$-phages
Fig. 3 By indenting liposomes with the tip of an atomic force microscope, Liang et al. were able to monitor the rupturing process on the force-distance curves (redrawn after Liang et al. [60])

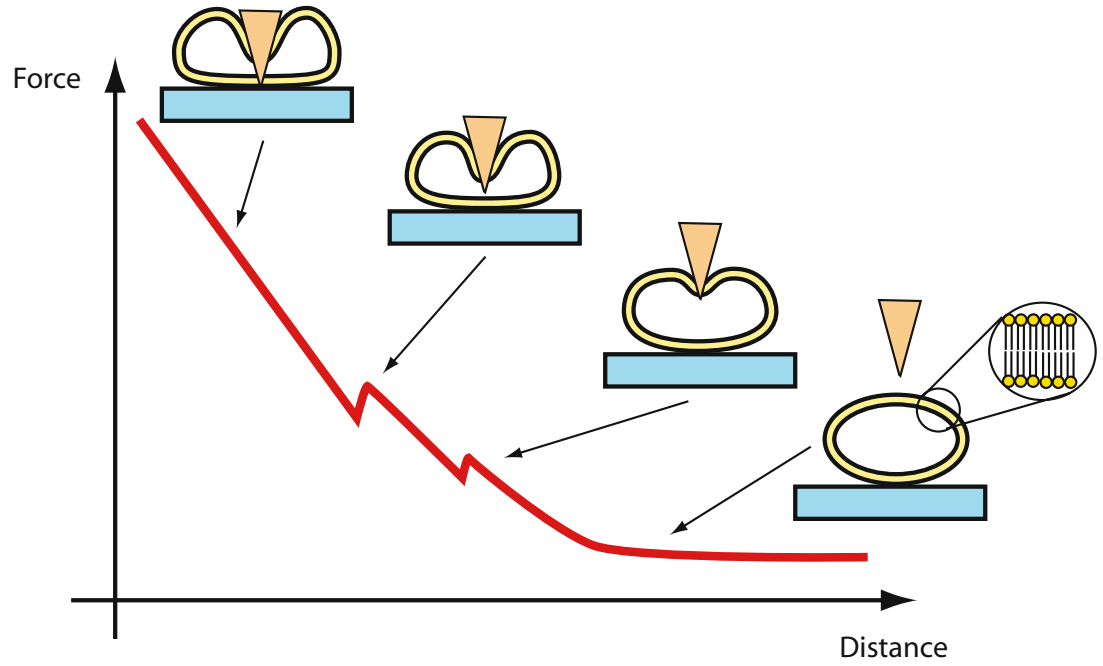




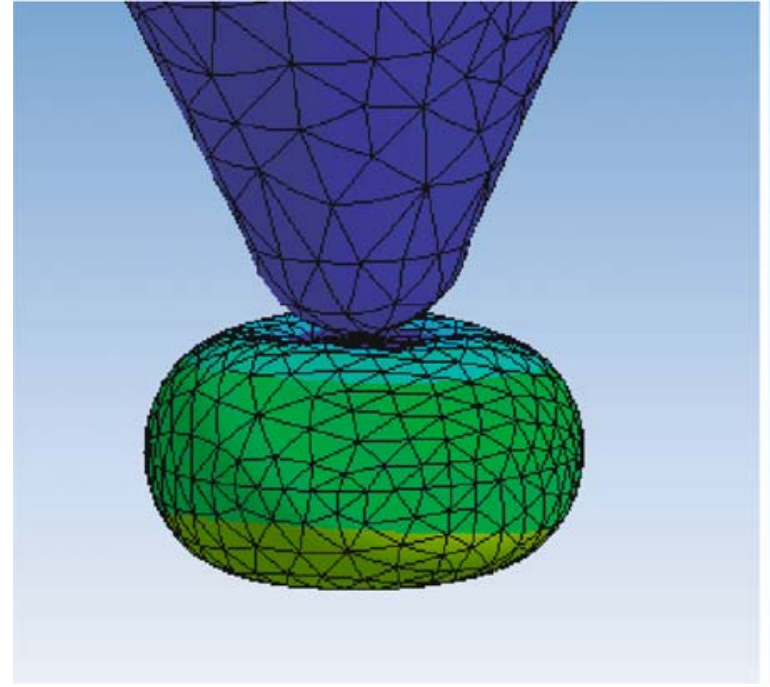

a

Fig. 4 An example of how finite-element modeling can be used to interpret the indentation of viral capsid in terms of continuum mechanics. In a, the tip of an atomic force microscope is seen to

had a spring constant that was nearly double that of empty of partially filled ones, and they could withstand forces twice as high before irreversible damage occurred. Using an appropriate analytical model, the authors demonstrated that the degree of pressure* exerted on the capsid in accordance with its DNA-packaging density had a considerable influence on its strength. Hence, the wild-type strain appears to have optimized its dimensions with respect to internal pressure and capsid strength.

Several years ago, Kol et al. [52] used AFM to determine the mechanical properties of the murine leukemia virus as a function of its maturation. Very recently, the same authors [53] have used this technique to measure the mechanical properties of the human immunoinsufficiency virus (HIV), likewise as a function of maturity. The immature particles were found to be 14-fold stiffer than mature ones. Finite-element modeling yielded a Young's modulus of $930 \mathrm{MPa}$ for the immature HIV capsid and one of $115 \mathrm{MPa}$ for the mature form. A striking correlation was found to exist between the softening of the virus during its maturation and its capacity to penetrate cells. The softening of the HIV envelope during its maturation was attributed to the emergence of the cytoplasmic tail domain. These data afford the first evidence of the important role played by the mechanical properties of a virus in its infection process. They further indicate that the HIV can regulate its mechanical properties at different stages of its life cycle.

\section{Microbes and diatoms}

As with viruses, AFM has now become the method of choice for studying the morphology of bacteria. And the

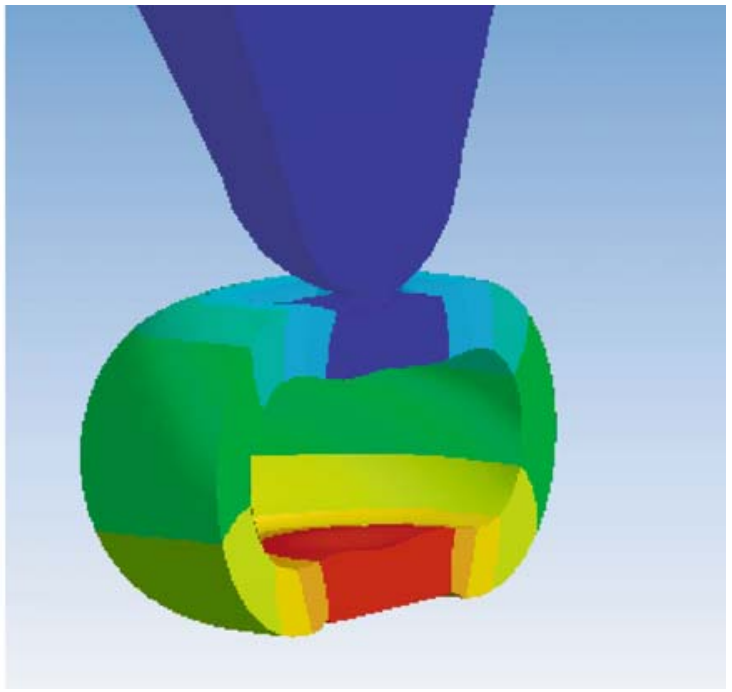

b

compress the sample. The elements of which each body is composed are outlined. In $\mathbf{b}$, the viral capsid has been sliced to reveal the colorcoded displacement vector

technique is the only one that has been implemented to probe their mechanical properties on the nanometric scale. The latter topic has been comprehensively reviewed by Gaboriaud and Dufrene [24].

In a pioneering study conducted by $\mathrm{Xu}$ et al. [99], in 1996, AFM was applied to measure the elastic modulus of the sheath of Methanospirillum hungatei GP1. Young's modulus was found to be remarkably high, the range of values calculated (20-40 GPa) indicating that the strength of the sheath is sufficient to withstand an internal pressure of up to 400 atmospheres.

Several years later, Velegol and Logan [93] used AFM to probe the mechanical properties of three different strains of Escherichia coli, the surfaces of which are characterized by different lipopolysaccharide lengths. The authors wished to gauge the influence of lipopolysaccharides on the adhesive and elastic properties of the bacterium. The force curves did not differ between the three strains, thereby indicating the absence of a steric contribution by lipopolysaccharides. The effective spring constant of the cells was increased fourfold after their fixation glutaraldehyde.

Prokaryotic organisms depend largely on diffusion for the uptake of nutrients and the elimination of waste products. This circumstance accounts for the extremely high chemical gradients that exist between the cytoplasm and the external environment. As the bacterial cytoplasm is much more concentrated than the external environment, large turgor pressures are generated within the cell which must be resisted by the wall to prevent bursting. This topic has been comprehensively tackled by Yao et al. [102]. In this study, AFM was applied to measure the turgor pressures of Enterococcus hirae (Gram-positive) and P. aeruginosa 
(Gram-negative) by deformation of the cell envelope. The data were analyzed using a complex mathematical model, which yielded a turgor pressure of $400-600 \mathrm{kPa}$ for E. hirae and one of $10-20 \mathrm{kPa}$ on P. aeruginosa.

The envelope of Gram-negative bacteria is composed of plasma membrane (lipid bilayer), which abuts on the cytoplasm, a periplasmic space (consisting of a strong polymer embedded within a concentrated gel-like matrix), and an outer membrane (likewise a lipid bilayer). The outer membrane can be mantled with extracellular biopolymers or bear specific external structures, such as fimbriae, pili, or flagellae. The biopolymers that cover the outer membrane influence the adhesion of the bacterium to all types of surface, from inorganic materials to other living cells. Abu-Lail and Camesano [2] have applied AFM to determine the spring constant of the biopolymeric coating (or brush layer) of Pseudomonas putida at different bathing concentrations of potassium chloride. At low ionic strengths, the brush layer extended up to a distance of $440 \mathrm{~nm}$ from the cell surface due to electrostatic repulsion. It was flaccid and had a spring constant of $0.014 \mathrm{nN} / \mathrm{nm}$. At a higher concentration of potassium chloride $(1 \mathrm{M})$, the brush layer retracted to a distance of $120 \mathrm{~nm}$ from the cell surface, and its rigidity increased to $0.114 \mathrm{nN} / \mathrm{nm}$ (see Fig. 5).

A similar kind of study was conducted by Gaboriaud et al. [23] using Shewanella putrefaciens, which is implicated in pathologies such as bacteremia, soft-tissue infections, and otitis media [45]. In this work, the authors investigated the mechanical properties of the bacterial envelope as a function of $\mathrm{pH}$. The spring constant was measured to be $0.05 \mathrm{~N} / \mathrm{m}$ at a pH of 4 and $0.02 \mathrm{~N} / \mathrm{m}$ at a pH of 10. Corresponding values for Young's modulus were 0.21 and $0.037 \mathrm{MPa}$, respectively. The force-distance curves revealed two distinct mechanical regimes: a linear one, which was interpreted as a progressive compression of the plasmic membrane that is maintained by turgor pressure, and a non-linear one which associated with a progressive compression of the polymeric fringe. The authors concluded that a rise in $\mathrm{pH}$ elicits a concurrent increase in the height and a decrease in the stiffness of the polymeric fringe (see Fig. 6). a

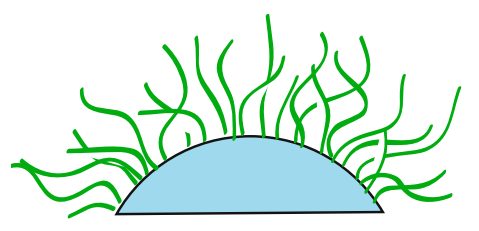

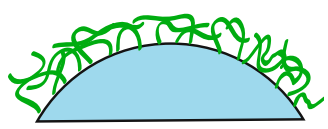

b
Fig. 5 Schematic representations of the biopolymeric coating (brush layer) of a Gram-negative bacterium at low (a) and high (b) bathing concentrations of potassium chloride (redrawn from Abu-Lail and Camesano [2])

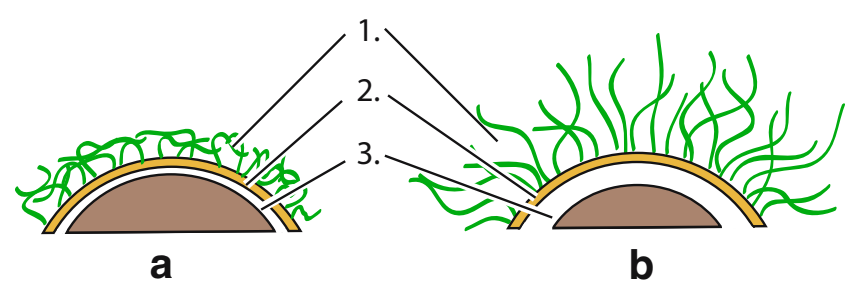

Fig. 6 Schematic representations of the envelope of a Gram-negative bacterium, which is composed of a polymeric fringe (1), an outer membrane (2), a periplasmic space (3), and an inner membrane (4), at $\mathrm{pH} 10$ (a) and pH 4 (b); (redrawn, not to scale, from Gaboriaud et al. [23])

Touhami et al. [92] have applied AFM in the forcemapping mode to demonstrate local variations in the cellwall elasticity of Saccharomyces cerevisiae. During cell division, chitin accumulates within the region of the cell wall that is involved in budding. Young's modulus was found to be tenfold higher in the region of a bud scar (6.1 MPa) than in other surface locations ( $0.6 \mathrm{MPa})$. This study was one of the first to use AFM force curves to spatially resolve regions of different elasticity on the surfaces of single microbial cells.

Numerous multicellular organisms produce protective antimicrobial peptides, which participate in their innate immune systems. Given the growing problem of bacterial resistance to conventional antibiotics, a great interest has arisen in the pharmacological application of antimicrobial peptides to treat infection. In this context, da Silva et al. $[16,17]$ have investigated the effect of an antimicrobial peptide that was isolated from the skin of frogs on E. coli. The topography of the cells and their stiffness were monitored by AFM before and after an injection of the peptide. The peptide induced first a disruption of the outer membrane, then a retraction of the pili, and finally a complete rupturing of the cell. These events were accompanied by a decrease in the stiffness of the bacterial wall, the spring constant dropping from $0.27 \mathrm{~N} / \mathrm{m}$ (before injection) to $0.01 \mathrm{~N} / \mathrm{m}$ (after injection and immediately before cell rupture).

Diatoms are single-celled algae bearing two hard siliceous coverings (frustules), which fit together in a boxand-lid-like fashion and which probably serve as a protective physical barrier against mechanical stress. There exists a striking similarity between the microscopic appearance of certain diatoms and statically sophisticated manmade constructions that combine the properties of rigidity and lightness. In all probability, the siliceous coverings of diatoms have been evolutionarily optimized to support the greatest possible stresses with the minimal amount of material. This property of diatoms renders them of particular interest in the field of biomimetics, which deals with the development of novel composite materials that imitate natural biominerals. AFM is a very convenient tool 
to image and measure the mechanical properties of these microscopic structures, and several investigators have applied the technique either to measure their Young's moduli $[4,62]$ or to explore the mechanical properties of the extracellular polymeric substances that are involved in their adhesion and motility $[31,32]$.

\section{Eukaryotes}

Attempts to measure the mechanical properties of living eukaryotic cells by AFM began soon after the discovery of the technique. Experiments of this kind are fairly challenging. On the one hand, it is not easy to preserve the viability of the cells in the imaging chamber, let alone to indent them without inducing damage. On the other hand, owing to the anisotropy of living cells, the indentation curves cannot be readily fitted to the Hertz model, which is based on the assumption that the sample is flat, has infinite dimensions, is isotropic and homogeneous, and which is used to calculate Young's modulus. Hence, an interpretation of the data is difficult.

One of the first attempts was made in 1994 by Hoh and Schoenenberger [34] who monitored the increase in stiffness of Madin-Darby canine kidney cells after their exposure to glutaraldehyde. Successive force-distance curves recorded on top of the cells confirmed the feasibility of monitoring changes in the mechanical properties of living cells as a function of physical or chemical influences.

In 1996, Radmacher et al. [74] applied AFM in the force-mapping mode to monitor the mechanical properties of human platelets. The pseudonucleus, which comprises the cytosol and small vesicles, was found to be the softest part of these bodies (Young's modulus, 1.5-4 kPa), whereas the outer filamentous zone, which consists of bundles of actin filaments and microtubules, was up to tenfold stiffer (Young's modulus, 10-40 kPa).

In 2000, Rotsch and Radmacher [80] used AFM to monitor the effects of various drugs that are known to disrupt or stabilize different components of the cytoskeleton on the evolution of stiffness in living cells. The disruption of actin filaments always resulted in a marked decrease in the average elastic modulus, indications of the crucial role of these structures in the mechanical stability of eukaryotic cells. However, the disruption or chemical stabilization of microtubules was not observed to affect cell elasticity. A similar methodology has been used previously to influence the elasticity of these cells. In a previous study [78], the same authors used a similar methodology to investigate changes in the mechanical properties of Kupffer cells (liver macrophages) after the pharmacological disruption of actin filaments.

The regulation of arterial blood pressure is a highly complex process, which involves both the nervous and the endocrine systems. Amongst the influential hormones, aldosterone is one of the most important. It is secreted in response to a fall in blood pressure and acts on the kidney by effecting the resorption of electrolytes. However, this is not its sole effect. An increasing body of evidence indicates that aldosterone plays a role also in some pathologies, such as heart failure and endothelial dysfunction. AFM has been applied by various investigators $[68-70,87,88]$ to assess the influence of aldosterone on the mechanical properties of vascular endothelial cells. The data gleaned from these experiments indicate that this hormone effects a significant increase in the stiffness of the cells. However, the mechanisms underlying this response are currently unknown.

Numerous other cell types have been explored by AFM. These include, among others, cardiocytes [33], osteoblasts $[12,13,91]$, glia [29, 100], fibroblasts [28, 46, 98], erythrocytes $[8,20]$ (review), oocytes [103], and outer-hair cells of Corti's organ, [67, 89, 90, 95, 96].

As mentioned under "Microbes and diatoms", AFM has been successfully applied to reveal local variations in the cell-wall elasticity of Saccharomyces cerevisae [92]. This technique has also been applied to reveal local variations in the stiffness of the eukaryocytic plasma membrane. Although the cell membrane is a relatively homogeneous structure, it contains small cholesterol-rich domains that are referred to as rafts. By tagging the proteins that are located exclusively within the rafts, Roduit et al. [76] have identified these regions by force microscopy (Fig. 7) and have measured their relative stiffness (Young's modulus). The rafts were found to be $30 \%$ stiffer than non-raft domains.

The mechanical properties of several other subcellular structures have been investigated by AFM. These include the fluid-transport vesicles of vascular endothelial cells

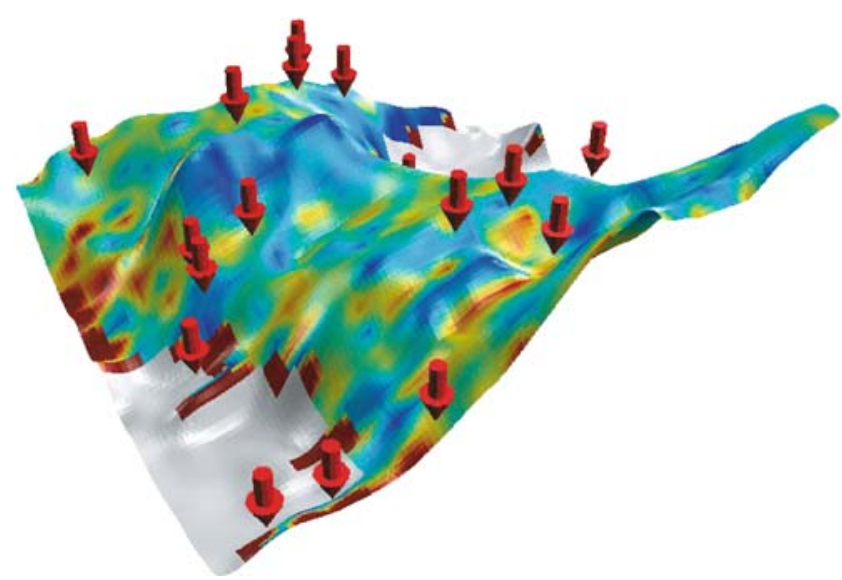

Fig. 7 Image of the surface of a eukaryocytic plasma membrane, which combines its topographic, chemical and mechanical features. The cholesterol-rich domains, or rafts, are denoted by arrows, while variations in Young's modulus are color-coded. The scanning size is $2 \mu \mathrm{m}$ (reproduced with the permission of C. Roduit) 
[75], neural growth cones [26], focal adhesions [22], and lamellipods $[55,79]$.

Several endeavors have been made to correlate cell stiffness with specific diseases. In 1999, Lekka et al. [58, 59] observed a significant change in the mechanical properties of cancerous cells compared to their normal counterparts. Both types had originated from the same line, the cancerous cells having been derived by transforming the normal ones with a v-ras oncogene. Similar attempts have been made using erythrocytes [20] that were derived from patients with various hereditary disorders, including spherocytosis, glucose-6-phosphate-dehydrogenase deficiency, thalassaemia, and anisocytosis of various causes. Young's modulus for the pathological erythrocytes was significantly higher than that for normal ones, thereby indicating that the cytoskeletal structures of the former and the latter might differ. Similar changes have been observed also for the erythrocytes of patients with diabetes mellitus [21]. Some neurological affections, such as multiple sclerosis, involve a degeneration of the myelin sheath, the destruction of which has profound consequences on nerve function. Heredia et al. [30] have applied AFM to determine the Young's modulus of myelinated and demyelinated axons. However, the calculated values did not differ significantly form each other. Studies relating to putative correlations between cellular mechanics and pathology have been reviewed by Costa [14] and Lee and Lim [56].

In most of the instances mentioned in this review, the AFM indentation curves were filled to the Hertz model, which is based on the assumption that the sample is flat, has infinite dimensions, is isotropic, and homogeneous. Such an assumption can lead to errors in the calculation of Young's modulus. Various algorithms [1] and alternative analytical methods have been implemented in an attempt to overcome this limitation. In one such instance [44], the living cells were assumed to behave mechanically as multilayered structures. This assumption permitted the authors to identify superficial and deep effects which were associated with the disassembly of actin and microtubules, respectively. Drug-induced destabilization of the actin filaments elicited a local decrease in viscoelasticity close to the cell membrane, whereas drug-induced destabilization of the microtubules effected a decrease in the stiffness of deeper portions of the cell.

\section{Discussion}

Thanks to the atomic force microscope, it has now become well established to measure the elastic and inelastic properties of biomolecules, complex structures, such as filaments, and even cells. The main asset of the microscope lies in the possibility that it affords of studying the mechanical properties of biological material under nearphysiological as well as under experimentally induced conditions. However, the complexity of biological structures poses a major challenge in the fitting of recorded data to an appropriate mathematical model, which is necessary to yield absolute values for the elastic modulus. And many factors external to the biological object must also be taken into account, including the geometry of the cantilever tip and its contact area with the sample. Most analytical models suffer from drawbacks, which relate principally to limitations in the geometrical shapes that can be mathematically handled. Finite-element modeling can facilitate the analytical process in that it permits at least an approximation of nearly all of the relevant factors. The complexity of the analysis is reflected in the broad range of values for the elastic modulus that have been calculated by different or even the same authors for any given biological structure. A very close fitting between the measurements and the numerical simulations is required to yield reliable and reproducible values. One important point that should be borne in mind is that the surface-to-volume ratios for nanometric structures will be dominated by the former parameter. Consequently, the interaction between the surface of a sample and its supporting substrate is of importance and could lead to a crucial effect. Finite-element modeling can be helpful in evaluating the cantilever response in such cases.

In the near future, improvements in data acquisition and in the speed of recording are expected. Indeed, online video imaging is currently under development. This facility could improve the temporal coupling of mechanical and topographic data collection, thereby permitting a closer comparison between local variations in elasticity and morphology. An increase in the recording speed would permit the coupling of dynamic changes in elasticity with topographic features.

\section{Appendix 1}

\subsection{Force}

The unit of force is the Newton $(\mathrm{N})$. One Newton is defined as the force that is produced by an object weighing $100 \mathrm{~g}$ (i.e., the weight of an average apple) on the surface of the Earth. As an example, the force generated by the interaction of a single myosin head with an actin filament is in the order of $1 \mathrm{pN}$ or $10^{-12} \mathrm{~N}$.

\subsection{Pressure}

Pressure is expressed in units of $\mathrm{N} / \mathrm{m}^{2}$, viz., in Pascals (Pa). The atmospheric pressure at sea level is about $100 \mathrm{kPa}$, 
whereas the pressure exerted by an AFM tip on a sample during contact scanning is approximately of $3 \mathrm{MPa}$.

\subsection{Young's modulus}

Young's modulus $(E)$ expresses the capacity of a sample to undergo elongation or compression when subjected to an external force. It is measured in Pascal units and is defined as stress $(\sigma)$ divided by strain $(\varepsilon)$ :

$E=\frac{\sigma}{\varepsilon}$.

Stress $(\sigma)$ is defined as force or load $(F)$ divided by the cross-sectional area of the sample $(A)$ :

$\sigma=\frac{F}{A}$,

and strain $(\varepsilon)$ as the normalized elongation of the specimen: (see also Fig. 8):

$\varepsilon=\frac{d L}{L}$

Young's modulus can be regarded as the stress that would be required to double the length of a sample if it does not break before this is achieved.

The Young's moduli for different materials are given in Fig. 9.

\subsection{Shear stress}

Shear stress is a measure of the tendency of one part of a solid to slide past a neighboring portion, as depicted in Fig. 10. If a cross-section of the material, having an area $A$, is acted upon by a shearing force $F$, then the shear stress generated within the material at that point $(N)$ will be:

$$
N=\frac{F}{A}
$$

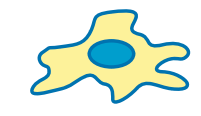

Cells

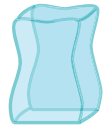

Gelatin

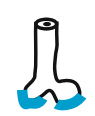

Cartilage
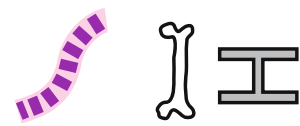

Collagen Bone Steel

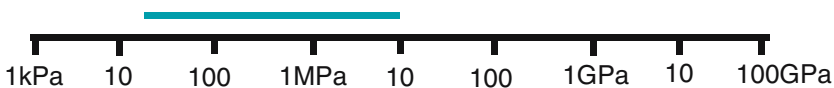

Fig. 8 Young's moduli for different materials. It is not possible to calculate Young's modulus for many soft biological materials, as their elastic behavior does not even approximately obey Hooke's law (modified from Alonso and Goldmann [5])

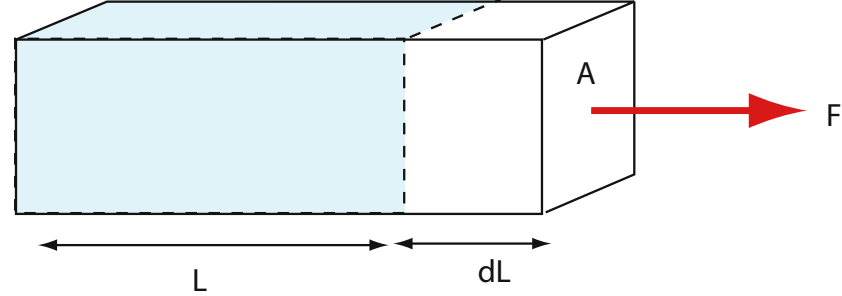

Fig. 9 Illustration of the phenomenon of strain. A force $(F)$ applied to the cross-sectional area $(A)$ of an object elicits an incremental increase $(d L)$ in its length $(L)$

\subsection{Shear strain}

All solids are strained when acted upon by shear stress, as they are when subjected to tensile stress. However, in the case of shear, the strain is angular and is usually measured in radians (see Fig. 11).

\subsection{Shear modulus}

When subjected to low or moderate stresses, most solids obey Hook's law in shear, much as they do in tension. Hence, if shear stress is plotted against shear strain, the relationship is initially linear. The gradient of the line represents the shear modulus $(G)$, which is expressed as:

$G=\frac{N}{g}$,

where ' $N$ ' is the shear stress and ' $g$ ' the angle through which the sample is distorted.

' $G$ ' is therefore an analogue of Young's modulus and can also be expressed as $\mathrm{N} / \mathrm{m}^{2}$ or Pascal units.

Fig. 10 Illustration of the phenomenon of shear stress, which is a measure of the tendency of one part of an object to slide past a neighboring portion. If a cross-section of the object, having an area $A$, is acted upon by a shearing force $F$, then the shear stress generated is given by $F / A$

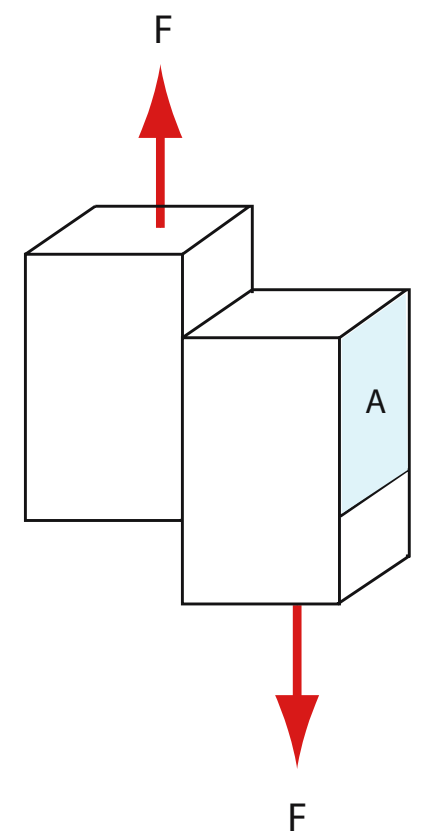




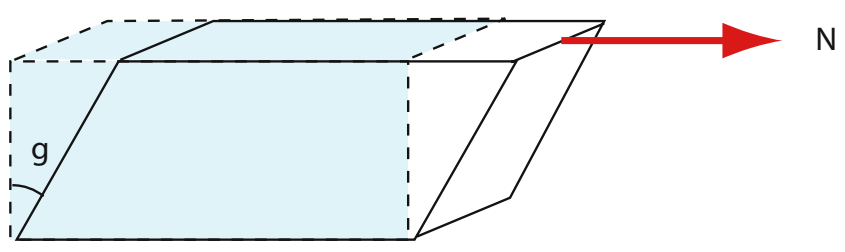

Fig. 11 Illustration of the phenomenon of shear strain, which is defined as the angle $(g)$ through which the sample is distorted as a result of shear stress $(N)$

The shear moduli of steel, microtubules, and rubber are $79 \mathrm{GPa}, 1.4 \mathrm{MPa}$, and $300 \mathrm{kPa}$, respectively.

\subsection{Spring constant}

If a sample has a complex shape, then difficulties may be experienced in calculating its Young's modulus. Consequently, some investigators prefer to consider the cantilever and the sample as two linear springs that are connected in series. In this case, the spring constant of the sample $\left(K_{\mathrm{s}}\right)$ is defined as:

$K_{s}=-K_{c}\left(\frac{S}{S+K_{c}}\right)$

Where ' $K_{\mathrm{c}}$ ' the spring constant of the cantilever and ' $S$ ' the slope of the approach curve (see below).

\subsection{Poisson's ratio}

Any sample that is subjected to an axial tension will exhibit some shrinkage in its lateral direction, as depicted in Fig. 12. The ratio of the lateral deformation to the axial deformation (i.e., strain) yields Poisson's ratio $(\mu)$ :

$\frac{d y}{y}=\mu \frac{d x}{x}$,

where ' $d y$ ' and ' $d x$ ' represent lateral displacements in the $x$ and $y$ directions, and ' $x$ ' and ' $y$ ' the side lengths of the sample.

Poisson's ratio for most metals, as well as for stone and concrete, lies in the range $0.25-0.35$. Biological solids have higher values, often of about 0.5 , and they are therefore incompressible.

\subsection{Bending modulus}

A beam or a membrane presents an elastic resistance to being curved or "bent." It arises because on one side of the midplane, the material is stretched, while it is compressed on the other side. The resistance of the material to these tensile and compressive forces determines the bending modulus. For a beam, it depends on the Young's modulus of the material and the second moment of inertia which is determined by the geometry of the cross-section.

\section{Appendix 2. Measurement the mechanical properties of biological samples by AFM}

\subsection{Force-distance curves}

The resistance of a sample to deformation (i.e., Young's modulus) is most commonly measured by applying an external force to it and following the process of deformation. The behavior of the cantilever is generally assumed to follow Hook's law:

$F=K_{c} d x$,

where ' $F$ ' is the force applied, ' $K_{\mathrm{c}}$ ' the spring constant of the cantilever, and ' $\mathrm{dx}$ ' the amplitude of cantilever bending.

The external force is generated by pushing the sample against the cantilever, the bending of which is proportional to the load applied. Knowing the degree to which the sample is displaced in the vertical direction by the piezo and the amplitude of cantilever bending, then it is possible to calculate the total external force that has been applied and the resulting deformation of the sample. In a typical measurement, the sample is moved vertically by a piezo and brought into contact with the tip of the cantilever to effect its bending. If the sample is soft, then the tip indents (i.e., penetrates) it, and the final bending of the cantilever is less than the vertical movement of the piezo. If the sample is hard, then the tip does not indent it, and the banding of the cantilever corresponds to the vertical distance covered by the piezo in the interval that elapses between moment of contact and the end of the displacement. The entire measurement process is illustrated in Fig. 13.
Fig. 12 If tensile stress $(F)$ is applied to an object, the material will undergo elongation $(d x)$ and lateral contraction $(d y)$

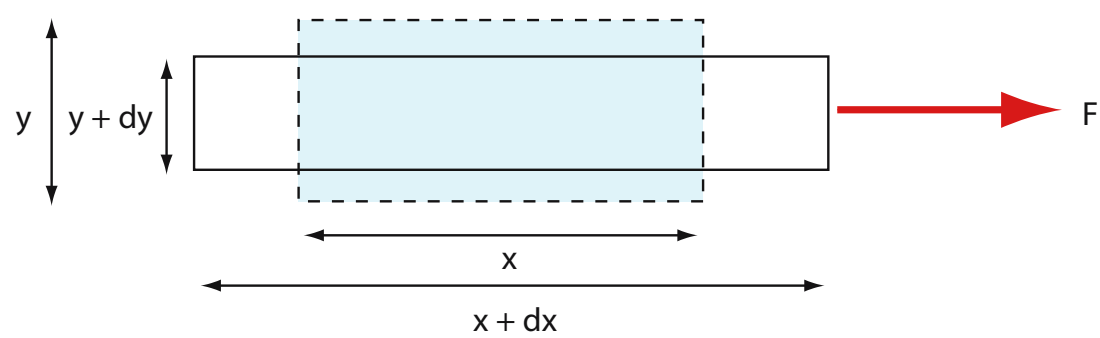




\section{$\sqrt{d}$}

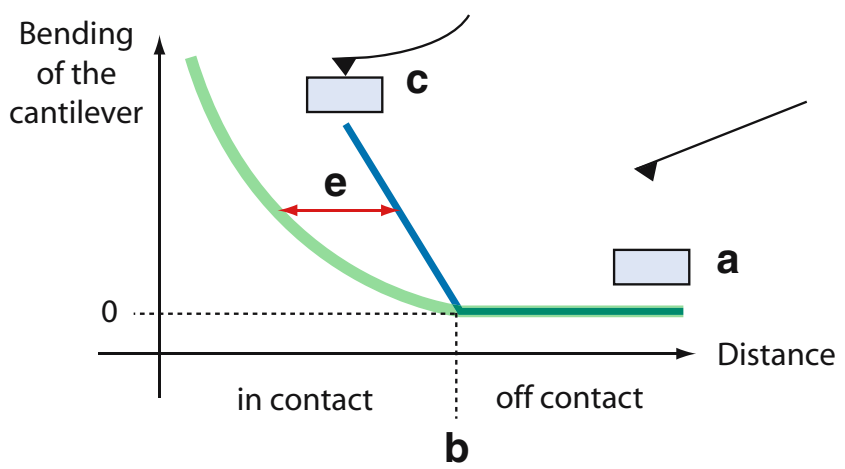

Fig. 13 Scheme illustrating the steps involved in the evolution of a force-distance curve (only the extension part of which is depicted). (a) When the tip of the cantilever is away from the sample, the cantilever is not bent. (b) At the moment that the tip touches the sample, the cantilever begins to bend. (c) If the sample is much stiffer than the cantilever, then it is not indented, and the bending of the cantilever is proportional to the extension of the piezo. (d) If the sample is soft, then the tip indents it, and the bending of the cantilever follows an inward course. (e) The indentation curve is derived for each force (i.e., the amplitude of cantilever bending) by measuring the distance between the curves $(c)$ and $(d)$

\subsection{Indentation curves}

The curve that describes the bending of the cantilever as a function of the sample's (i.e., the piezo's) position is referred to as a force-distance curve. A so-called indentation curve is obtained by subtracting the force-distance curve that has been recorded for the sample from one that has been recorded for a hard surface. The indentation curve yields information respecting the force that is required to push the tip into a defined depth of the sample. This is the curve that is required to calculate Young's modulus of the sample. Young's modulus is obtained by fitting the experimental force-distance to one of several available theoretical indentation models (Fig. 14), such as those elaborated by Hertz, Sneddon, JKR, and Tatara. The Hertz model describes the elastic deformation of two spheres, whereas Sneddon's model extends the calculation to other geometries. However, it should be borne in mind that these models do not account for long-range electrostatic or ionic forces. The different models and their limitations have been comprehensively reviewed by Cappella and Dietler [11] and Butt et al. [9].

\subsection{Force mapping}

A natural extension to the recording of force-distance and indentation curves was the acquisition of complete maps of the material properties of the sample. The mapping technique, which is referred to as force mapping or force- volume imaging involves the recording of force-distance curves over the entire surface of the sample. From the individual force-distance curves, it is possible to obtain topographic images of each location at a given force.

\subsection{Force modulation}

Force modulation involves the application of a modulating frequency in the order of several tens of kilohertz to the tip of the cantilever during the scanning process and the monitoring of its bending. Under these conditions, a stiff area on the sample will deform less than a soft one. Consequently, stiffer areas will offer a higher resistance to the vertical oscillations of the cantilever, thereby causing its greater bending. The amplitude of the bending gives a measure of the relative stiffness of the surface of the sample. Despite the technical simplicity of the method, it does not consistently yield reproducible and quantifiable data for cell samples.

\subsection{Finite-elements modeling}

Finite-element modeling is a numerical analysis technique, which is implemented by engineers to yield solutions to the differential equations that describe the behavior of solids and fluids. The method is based on the premises that a complicated domain can be subdivided into smaller regions (elements) for which the differential equations can be approximately solved. By assembling the sets of equations for each region, the behavior of the entire problem domain can be approximated. Finite-element modeling was essentially developed for the field of structural engineering, but was later applied to fluids and electromagnetic problems. An increasing number of investigators are now using finiteelement modeling to interpret their AFM data [15]. The applications of this analytical tool to microscopic samples have been comprehensively reviewed by Ikai [36].

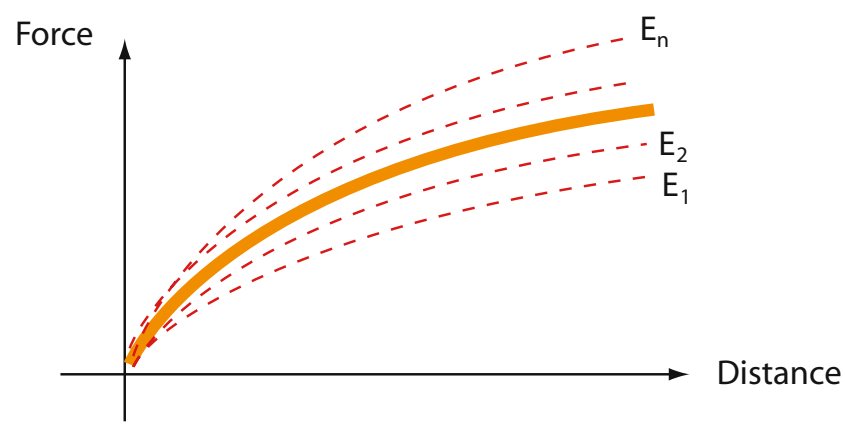

Fig. 14 The experimental indentation curve (orange) is fitted to theoretically-modeled ones (red: $E_{1}-E_{\mathrm{n}}$ ) to yield the Young's modulus for the sample 


\section{References}

1. A-Hassan E, Heinz WF, Antonik MD, D'Costa NP, Nageswaran S, Schoenenberger CA, Hoh JH (1998) Relative microelastic mapping of living cells by atomic force microscopy. Biophys J 74:15641578

2. Abu-Lail NI, Camesano TA (2003) Polysaccharide properties probed with atomic force microscopy. J Microsc (Oxford) 212:217-238

3. Afrin R, Alam MT, Ikai A (2005) Pretransition and progressive softening of bovine carbonic anhydrase II as probed by single molecule atomic force microscopy. Protein Sci 14:1447-1457

4. Almqvist N, Delamo Y, Smith BL, Thomson NH, Bartholdson A, Lal R, Brzezinski M, Hansma PK (2001) Micromechanical and structural properties of a pennate diatom investigated by atomic force microscopy. J Microsc (Oxford) 202:518-532

5. Alonso JL, Goldmann WH (2003) Feeling the forces: atomic force microscopy in cell biology. Life Sci 72:2553-2560

6. Bhyravbhatla B, Watowich SJ, Caspar DLD (1998) Refined atomic model of the four-layer aggregate of the tobacco mosaic virus coat protein at 2.4-angstrom resolution. Biophys J 74:604615

7. Bloom S, Lockard VG, Bloom M (1996) Intermediate filamentmediated stretch-induced changes in chromatin: a hypothesis for growth initiation in cardiac myocytes. J Mol Cell Cardiol 28:2123-2127

8. Bremmell KE, Evans A, Prestidge CA (2006) Deformation and nano-rheology of red blood cells: An AFM investigation. Colloids Surf B Biointerfaces 50:43-48

9. Butt HJ, Cappella B, Kappl M (2005) Force measurements with the atomic force microscope: Technique, interpretation and applications. Surf Sci Rep 59:1-152

10. Calakos N, Scheller RH (1996) Synaptic vesicle biogenesis, docking, and fusion: a molecular description. Physiol Rev 76:1-29

11. Cappella B, Dietler G (1999) Force-distance curves by atomic force microscopy. Surf Sci Rep 34:1-104

12. Charras GT, Horton MA (2002) Single cell mechanotransduction and its modulation analyzed by atomic force microscope indentation. Biophys J 82:2970-2981

13. Charras GT, Lehenkari PP, Horton MA (2001) Atomic force microscopy can be used to mechanically stimulate osteoblasts and evaluate cellular strain distributions. Ultramicroscopy 86:85-95

14. Costa KD (2003) Single-cell elastography: probing for disease with the atomic force microscope. Dis Markers 19:139-154

15. Costa KD, Yin FCP (1999) Analysis of indentation: implications for measuring mechanical properties with atomic force microscopy. J Biomech Eng-Trans Am Soc Mech Eng 121: 462-471

16. da Silva A, Teschke O (2005) Dynamics of the antimicrobial peptide PGLa action on Escherichia coli monitored by atomic force microscopy. World J Microbiol Biotechnol 21:1103-1110

17. da Silva A, Teschke O (2003) Effects of the antimicrobial peptide PGLa on live Escherichia coli. Biochim Biophys ActaMol Cell Res 1643:95-103

18. de Pablo PJ, Schaap IAT, MacKintosh FC, Schmidt CF (2003) Deformation and collapse of microtubules on the nanometer scale. Phys Rev Lett 91:098101

19. Drewes G, Ebneth A, Mandelkow EM (1998) MAPs, MARKs and microtubule dynamics. Trends Biochem Sci 23:307-311

20. Dulinska I, Targosz M, Strojny W, Lekka M, Czuba P, Balwierz W, Szymonski M (2006) Stiffness of normal and pathological erythrocytes studied by means of atomic force microscopy. J Biochem Biophys Methods 66:1-11
21. Fornal M, Lekka M, Pyka-Fosciak G, Lebed K, Grodzicki T, Wizner B, Styczen J (2006) Erythrocyte stiffness in diabetes mellitus studied with atomic force microscope. Clin Hemorheol Microcirc 35:273-276

22. Franz CM, Muller DJ (2005) Analyzing focal adhesion structure by atomic force microscopy. J Cell Sci 118:5315-5323

23. Gaboriaud F, Bailet S, Dague E, Jorand F (2005) Surface structure and nanomechanical properties of Shewanella putrefaciens bacteria at two $\mathrm{pH}$ values (4 and 10) determined by atomic force microscopy. J Bacteriol 187:3864-3868

24. Gaboriaud F, Dufrene YF (2007) Atomic force microscopy of microbial cells: application to nanomechanical properties, surface forces and molecular recognition forces. Colloids Surf B Biointerfaces 54:10-19

25. Gibbons MM, Klug WS (2007) Nonlinear finite-element analysis of nanoindentation of viral capsids. Phys Rev E 75:031901

26. Grzywa EL, Lee AC, Lee GU, Suter DM (2006) Highresolution analysis of neuronal growth cone morphology by comparative atomic force and optical microscopy. J Neurobiol 66:1529-1543

27. Guzman C, Jeney S, Kreplak L, Kasas S, Kulik AJ, Aebi U, Forro L (2006) Exploring the mechanical properties of single vimentin intermediate filaments by atomic force microscopy. J Mol Biol 360:623-630

28. Haga H, Sasaki S, Kawabata K, Ito E, Ushiki T, Sambongi T (2000) Elasticity mapping of living fibroblasts by AFM and immunofluorescence observation of the cytoskeleton. Ultramicroscopy 82:253-258

29. Haydon PG, Lartius R, Parpura V, MarcheseRagona SP (1996) Membrane deformation of living glial cells using atomic force microscopy. J Microsc (Oxford) 182:114-120

30. Heredia A, Bui CC, Suter U, Young P, Schaffer TE (2007) AFM combines functional and morphological analysis of peripheral myelinated and demyelinated nerve fibers. Neuroimage 37: $1218-1226$

31. Higgins MJ, Molino P, Mulvaney P, Wetherbee R (2003) The structure and nanomechanical properties of the adhesive mucilage that mediates diatom-substratum adhesion and motility. J Phycol 39:1181-1193

32. Higgins MJ, Sader JE, Mulvaney P, Wetherbee R (2003) Probing the surface of living diatoms with atomic force microscopy: the nanostructure and nanomechanical properties of the mucilage layer. J Phycol 39:722-734

33. Hofmann UG, Rotsch C, Parak WJ, Radmacher M (1997) Investigating the cytoskeleton of chicken cardiocytes with the atomic force microscope. J Struct Biol 119:84-91

34. Hoh JH, Schoenenberger CA (1994) Surface-morphology and mechanical-properties of Mdck monolayers by atomic-force microscopy. J Cell Sci 107:1105-1114

35. Ikai A (2005) Local rigidity of a protein molecule. Biophys Chemist 116:187-191

36. Ikai A (2008) The world of nano-biomechanics. Elsevier, Amsterdam

37. Ikai A, Afrin R, Sekiguchi H (2007) Pulling and pushing protein molecules by AFM. Current Nanoscience 3:17-29

38. Ivanovska I, Wuite G, Jonsson B, Evilevitch A (2007) Internal DNA pressure effect on the phage capsid stability. Evolutionary optimization of phage. Biophys J 49A (abstract)

39. Ivanovska I, Wuite G, Jonsson B, Evilevitch A (2007) Internal DNA pressure modifies stability of WT phage. Proc Natl Acad Sci U S A 104:9603-9608

40. Ivanovska IL, Agirrezabala X, Carrascosa JL, Schmidt CF, Wuite GJL (2007) Deconstructing viral capsids reveals their strengths and weaknesses. Biophys J 49A (abstract) 
41. Jiao Y, Schaffer TE (2004) Accurate height and volume measurements on soft samples with the atomic force microscope. Langmuir 20:10038-10045

42. Kasas S, Dietler G (2007) Techniques for measuring microtubule stiffness. Current Nanoscience 3:85-96

43. Kasas S, Kis A, Riederer BM, Forro L, Dietler G, Catsicas S (2004) Mechanical properties of microtubules explored using the finite elements method. ChemPhysChem 5:252-257

44. Kasas S, Wang X, Hirling H, Marsault R, Huni B, Yersin A, Regazzi R, Grenningloh G, Riederer B, Forro L, Dietler G, Catsicas S (2005) Superficial and deep changes of cellular mechanical properties following cytoskeleton disassembly. Cell Motil Cytoskelet 62:124-132

45. Khashe S, Janda JM (1998) Biochemical and pathogenic properties of Shewanella alga and Shewanella putrefaciens. J Clin Microbiol 36:783-787

46. Kidoaki S, Matsuda T, Yoshikawa K (2006) Relationship between apical membrane elasticity and stress fiber organization in fibroblasts analyzed by fluorescence and atomic force microscopy. Biomechanics and Modeling in Mechanobiology 5:263-272

47. Kis A, Kasas S, Babic B, Kulik AJ, Benoit W, Briggs GAD, Schonenberger C, Catsicas S, Forro L (2002) Nanomechanics of microtubules. Phys Rev Lett 89:248101

48. Klug WS, Bruinsma RF, Michel JP, Knobler CM, Ivanovska IL, Schmidt CF, Wuite GJL (2006) Failure of viral shells. Phys Rev Lett 97:228101

49. Klug WS, Bruinsma RF, Michel JP, Knobler CM, Ivanovska IL, Schmidt CF, Wuite GJL (2007) Mechanical failure of viral shells. Biophys J 532A (abstract)

50. Kodama T, Ohtani H, Arakawa H, Ikai A (2005) Mechanical perturbation-induced fluorescence change of green fluorescent protein. Appl Phys Lett 86:043901

51. Kodama T, Ohtani H, Arakawa H, Ikai A (2005) Observation of the destruction of biomolecules under compression force. Ultramicroscopy 105:189-195

52. Kol N, Gladnikoff M, Barlam D, Shneck RZ, Rein A, Rousso I (2006) Mechanical properties of murine leukemia virus particles: effect of maturation. Biophys J 91:767-774

53. Kol N, Shi Y, Tsvitov M, Barlam D, Shneck RZ, Kay MS, Rousso I (2007) A stiffness switch in human immunodeficiency virus. Biophys J 92:1777-1783

54. Laney DE, Garcia RA, Parsons SM, Hansma HG (1997) Changes in the elastic properties of cholinergic synaptic vesicles as measured by atomic force microscopy. Biophys J 72:806-813

55. Laurent VM, Kasas S, Yersin A, Schaffer TE, Catsicas S, Dietler G, Verkhovsky AB, Meister JJ (2005) Gradient of rigidity in the lamellipodia of migrating cells revealed by atomic force microscopy. Biophys J 89:667-675

56. Lee GYH, Lim CT (2007) Biomechanics approaches to studying human diseases. Trends Biotech 25:111-118

57. Lee VMY, Goedert M, Trojanowski JQ (2001) Neurodegenerative tauopathies. Ann Rev Neurosci 24:1121-1159

58. Lekka M, Laidler P, Gil D, Lekki J, Stachura Z, Hrynkiewicz AZ (1999) Elasticity of normal and cancerous human bladder cells studied by scanning force microscopy. Eur Biophys J Biophys Lett 28:312-316

59. Lekka M, Lekki J, Marszalek M, Golonka P, Stachura Z, Cleff B, Hrynkiewicz AZ (1999) Local elastic properties of cells studied by SFM. Appl Surf Sci 141:345-349

60. Liang XM, Mao GZ, Ng KYS (2004) Mechanical properties and stability measurement of cholesterol-containing liposome on mica by atomic force microscopy. J Colloid Interface Sci 278:53-62

61. Liang XM, Mao GZ, Ng KYS (2004) Probing small unilamellar EggPC vesicles on mica surface by atomic force microscopy. Colloids Surf B Biointerfaces 34:41-51
62. Losic D, Short K, Mitchell JG, Lal R, Voelcker NH (2007) AFM nanoindentations of diatom biosilica surfaces. Langmuir 23: 5014-5021

63. Maniotis AJ, Chen CS, Ingber DE (1997) Demonstration of mechanical connections between integrins cytoskeletal filaments, and nucleoplasm that stabilize nuclear structure. Proc Natl Acad Sci U S A 94:849-854

64. Michel JP, Ivanovska IL, Gibbons MM, Klug WS, Knobler CM, Wuite GJL, Schmidt CF (2006) Nanoindentation studies of full and empty viral capsids and the effects of capsid protein mutations on elasticity and strength. Proc Natl Acad Sci U S A 103:6184-6189

65. Mitchison T, Kirschner M (1984) Dynamic instability of microtubule growth. Nature 312:237-242

66. Munson KM, Mulugeta PG, Donhauser ZJ (2007) Enhanced mechanical stability of microtubules polymerized with a slowly hydrolyzable nucleotide analogue. J Phys Chem B 111:50535057

67. Murakoshi M, Yoshida N, Iida K, Kumano S, Kobayashi T, Wada H (2006) Local mechanical properties of mouse outer hair cells: atomic force microscopic study. Auris Nasus Larynx 33:149-157

68. Oberleithner H (2005) Aldosterone makes human endothelium stiff and vulnerable. Kidney Int 67:1680-1682

69. Oberleithner H, Riethmuller C, Ludwig T, Shahin V, Stock C, Schwab A, Hausberg M, Kusche K, Schillers H (2006) Differential action of steroid hormones on human endothelium. J Cell Sci 119:1926-1932

70. Ohashi T, Ishii Y, Ishikawa Y, Matsumoto T, Sato M (2002) Experimental and numerical analyses of local mechanical properties measured by atomic force microscopy for sheared endothelial cells. Bio-med Mater Eng 12:319-327

71. Parpura V, Fernandez JM (1996) Atomic force microscopy study of the secretory granule lumen. Biophys J 71:2356-2366

72. Parra A, Casero E, Lorenzo E, Pariente F, Vazquez L (2007) Nanomechanical properties of globular proteins: lactate oxidase. Langmuir 23:2747-2754

73. Radmacher M, Fritz M, Cleveland JP, Walters DA, Hansma PK (1994) Imaging adhesion forces and elasticity of lysozyme adsorbed on mica with the atomic-force microscope. Langmuir 10:3809-3814

74. Radmacher M, Fritz M, Kacher CM, Cleveland JP, Hansma PK (1996) Measuring the viscoelastic properties of human platelets with the atomic force microscope. Biophys J 70:556-567

75. Riethmueller C, Schaeffer TE, Kienberger F, Stracke W, Oberleithner H (2007) Vacuolar structures can be identified by AFM elasticity mapping. Ultramicroscopy 107:895-901

76. Roduit C, Van der Goot G, De Los Rios P, Yersin A, Steiner P, Dietler G, Catsicas S, Lafont F, Kasas S (2007) Elastic membrane heterogeneity of living cells revealed by stiff nanoscale membrane domains. Biophys J 107:112862

77. Roos WH, Ivanovska IL, Evilevitch A, Wuite GJL (2007) Viral capsids: mechanical characteristics, genome packaging and delivery mechanisms. Cell Mol Life Sci 64:1484-1497

78. Rotsch C, Braet F, Wisse E, Radmacher M (1997) AFM imaging and elasticity measurements on living rat liver macrophages. Cell Biol Int 21:685-696

79. Rotsch C, Jacobson K, Condeelis J, Radmacher M (2001) EGFstimulated lamellipod extension in adenocarcinoma cells. Ultramicroscopy 86:97-106

80. Rotsch C, Radmacher M (2000) Drug-induced changes of cytoskeletal structure and mechanics in fibroblasts: an atomic force microscopy study. Biophys J 78:520-535

81. Schaap I, de Pablo PJ, Schmidt C (2003) Elastic properties of microtubules observed with scanning force microscopy. Biophys J 84:113A 
82. Schaap IAT, Carrasco C, de Pablo PJ, MacKintosh FC, Schmidt CF (2006) Elastic response, buckling, and instability of microtubules under radial indentation. Biophys J 91:1521-1531

83. Schaap IAT, Carrasco C, Harder S, Hoffmann B, De Pablo PJ, Schmidt CF (2007) Cytoskeletal filaments and their associated proteins studied with atomic force microscopy. Biophys J 309A (abstract)

84. Schaap IAT, de Pablo PJ, Schmidt CF (2004) Resolving the molecular structure of microtubules under physiological conditions with scanning force microscopy. Eur Biophys J Biophys Lett 33:462-467

85. Schaap IAT, Hoffmann B, Carrasco C, Merkel R, Schmidt CF (2007) Tau protein binding forms a $1 \mathrm{~nm}$ thick layer along protofilaments without affecting the radial elasticity of microtubules. J Struct Biol 158:282-292

86. Schmatulla A, Maghelli N, Marti O (2007) Micromechanical properties of tobacco mosaic viruses. J Microsc (Oxford) 225: 264-268

87. Schrot S, Weidenfeller C, Schaffer TE, Galla HJ (2005) Morphology and elasticity studies of the cell-cell contacts at the blood brain barrier in vitro. Biophys J 88:495A

88. Schrot S, Weidenfeller C, Schaffer TE, Robenek H, Galla HJ (2005) Influence of hydrocortisone on the mechanical properties of the cerebral endothelium in vitro. Biophys J 89:3904-3910

89. Sugawara M, Ishida Y, Wada H (2002) Local mechanical properties of guinea pig outer hair cells measured by atomic force microscopy. Hear Res 174:222-229

90. Sugawara M, Ishida Y, Wada H (2004) Mechanical properties of sensory and supporting cells in the organ of Corti of the guinea pig cochlea - study by atomic force microscopy. Hear Res 192:57-64

91. Takai E, Costa KD, Shaheen A, Hung CT, Guo XE (2005) Osteoblast elastic modulus measured by atomic force microscopy is substrate dependent. Ann Biomed Eng 33:963-971

92. Touhami A, Nysten B, Dufrene YF (2003) Nanoscale mapping of the elasticity of microbial cells by atomic force microscopy. Langmuir 19:4539-4543

93. Velegol SB, Logan BE (2002) Contributions of bacterial surface polymers, electrostatics, and cell elasticity to the shape of AFM force curves. Langmuir 18:5256-5262
94. Vinckier A, Heyvaert I, Dhoore A, McKittrick T, Vanhaesendonck C, Engelborghs Y, Hellemans L (1995) Immobilizing and imaging microtubules by atomic-force microscopy. Ultramicroscopy 57:337-343

95. Wada H, Kimura K, Gomi T, Sugawara M, Katori Y, Kakehata S, Ikeda K, Kobayashi T (2004) Imaging of the cortical cytoskeleton of guinea pig outer hair cells using atomic force microscopy. Hear Res 187:51-62

96. Wada H, Usukura H, Sugawara M, Katori Y, Kakehata S, Ikeda K, Kobayashi T (2003) Relationship between the local stiffness of the outer hair cell along the cell axis and its ultrastructure observed by atomic force microscopy. Hear Res 177:61-70

97. Welte MA (2004) Bidirectional transport along microtubules. Curr Biol 14:R525-R537

98. Wu HW, Kuhn T, Moy VT (1998) Mechanical properties of 1929 cells measured by atomic force microscopy: Effects of anticytoskeletal drugs and membrane crosslinking. Scanning 20:389-397

99. Xu W, Mulhern PJ, Blackford BL, Jericho MH, Firtel M, Beveridge TJ (1996) Modeling and measuring the elastic properties of an archaeal surface, the sheath of Methanospirillum hungatei, and the implication for methane production. J Bacteriol 178:3106-3112

100. Yamane Y, Hatakeyama D, Tojima T, Kawabata K, Ushiki T, Ogura S, Abe K, Ito E (1998) Fine surface images that reflect cytoskeletal structures in cultured glial cells by atomic force microscopy. Japanese Journal of Applied Physics Part 1Regular Papers Short Notes \& Review Papers 37:3849-3854

101. Yang L, van der Werf KO, Koopman B, Subramaniam V, Bennink ML, Dijkstra PJ, Feijen J (2007) Micromechanical bending of single collagen fibrils using atomic force microscopy. J Biomed Mater Res Part A 82A:160-168

102. Yao X, Walter J, Burke S, Stewart S, Jericho MH, Pink D, Hunter R, Beveridge TJ (2002) Atomic force microscopy and theoretical considerations of surface properties and turgor pressures of bacteria. Colloids Surf B Biointerfaces 23:213-230

103. Zhao MH, Srinivasan C, Burgess DJ, Huey BD (2006) Rate- and depth-dependent nanomechanical behavior of individual living Chinese hamster ovary cells probed by atomic force microscopy. J Mater Res 21:1906-1912 